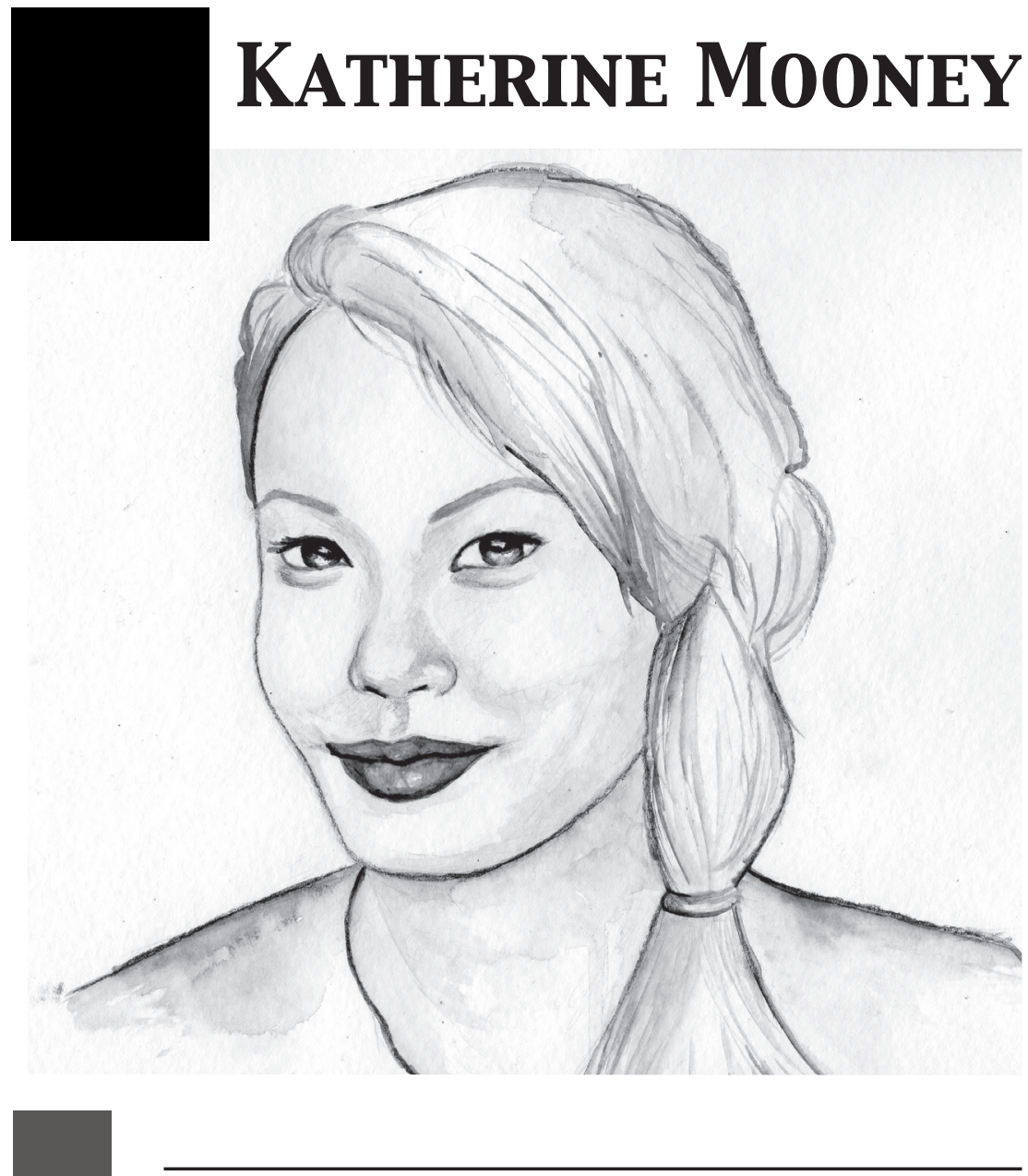

Katherine Mooney is, first and foremost, a gypsy soul wandering in a beautiful world. She is additionally a proud Pitt Panther, an English Literature and History double major aiming for a certificate in Medieval and Renaissance Studies, a member of the Class of 2016, and an avid lover of life. Besides musing on such topics as the passage of time, the transference of memories, and the progression of love, she also enjoys watercolor painting, reading Tolstoy, kayaking, singing, knitting, baking, and creating outlandish puns. 


\section{DEEP BLUE SEA}

I don't know how it happens

Just so

With a flourish, and is gone.

A slip, a fall, somewhere bruises form

on knees or elbows scrubbed raw

in the old metal tub.

I don't know how it happens

That one day we halt the coffee, or fold the newspaper,

put down the feet and stand up, wavering, uncertain and lost.

I don't know how it happens

how fleeting love can rise and fall

like an ever-flowing tide,

weeping, bringing abundant, destructive waters, and retreating far into dark, untrodden caves, leaving desolation and words floundering about like dying fish upon the beachside.

The sea breeze rusting your

metal locket, causing rashes on your ashen face.

I don't know how it happens

how understanding and compassion splinter,

one day,

out of the deep blue sea,

and you stand there, feet being cut by

the blades strewn across the rocks.

A barrier of salt and iron

stands defiant between you and where you once

saw sunlight dancing on the white-capped waves.

I just don't know how it happens

how it happens so suddenly, and yet

it is discovered over long amounts of time,

skipping rocks across the surface of

a riptide current that pulls you out to sea

for one purpose and one purpose only -

to drown you among the tangled seaweeds

and salty brine and crumbling shells.

Did you hear me?

To drown you in the great blue.

I don't know how it happens

and yet it did,

and now I cannot span this great sea between us. 